Diabetologia (2000) 43: 1126-1135

\title{
Contribution of visceral obesity to the deterioration of the metabolic risk profile in men with impaired glucose tolerance
}

\author{
A. Pascot ${ }^{1}$, J.P. Després ${ }^{2}$, I. Lemieux ${ }^{1}$, J. Bergeron ${ }^{1}$, A. Nadeau ${ }^{3}$, D. Prud'homme ${ }^{4}$, A. Tremblay ${ }^{4}$, S. Lemieux ${ }^{5}$ \\ ${ }^{1}$ Lipid Research Center, CHUL Research Center, Ste-Foy, Québec, Canada \\ ${ }^{2}$ Québec Heart Institute, Hôpital Laval Research Center, Ste-Foy, Québec, Canada \\ ${ }^{3}$ Diabetes Research Unit, CHUL Research Center, Ste-Foy, Québec, Canada \\ ${ }^{4}$ Division of Kinesiology, Laval University, Ste-Foy, Québec, Canada \\ ${ }^{5}$ Department of Food Science and Nutrition, Laval University, Ste-Foy, Québec, Canada
}

\begin{abstract}
Aims/hypothesis. Impaired glucose tolerance is associated with metabolic alterations which increase cardiovascular disease risk. The contribution of hyperglycaemia to this increased risk is, however, not clear. Abdominal obesity is often observed in subjects with impaired glucose tolerance; our objective was therefore to find the contribution of visceral adipose tissue to the deterioration of the metabolic risk profile noted in subjects with impaired glucose tolerance.

Methods. We studied 284 men with a normal glucose tolerance and 66 men with impaired glucose tolerance which was defined as a glycaemia between 7.8 and $11.1 \mathrm{mmol} / \mathrm{l} 2 \mathrm{~h}$ after a $75-\mathrm{g}$ glucose load.

Results. Men with impaired glucose tolerance had more visceral adipose tissue and higher concentrations of plasma glucose and insulin in the fasting state and following a 75-g oral glucose load than men with a normal glucose tolerance. They also had higher
\end{abstract}

concentrations of plasma cholesterol, triglycerides, apolipoprotein B and lower concentrations of HDLcholesterol as well as higher cholesterol:HDL-cholesterol ratios than men with a normal glucose tolerance. The two groups of men were then compared after a statistical adjustment for the amount of visceral adipose tissue. Although men with impaired glucose tolerance still had higher fasting plasma glucose and insulin concentrations after the adjustment for visceral adipose tissue, differences in all the variables of the lipid-lipoprotein profile were eliminated.

Conclusion/interpretation. Visceral adipose tissue accumulation is an important factor in the deterioration of the plasma lipid-lipoprotein noted in men with impaired glucose tolerance. [Diabetologia 2000 43: 1126-1135]

Keywords Impaired glucose tolerance, visceral obesity, lipid-lipoprotein, cardiovascular disease risk, men.
Cardiovascular disease (CVD) mortality rates are increased in people with impaired glucose tolerance (IGT) [1-6]. This observation suggests that hyperglycaemia is associated with CVD, although it does not necessarily confirm that glucose intolerance in itself is causal in CVD [5]. Impaired glucose tolerance is a frequently observed condition and its prevalence var-

Received: 16 March 2000 and in revised from 8 June 2000

Corresponding author: S. Lemieux $\mathrm{PhD}$, Department of Food Science and Nutrition, Laval University, Paul-Comtois Pavilion, Sainte-Foy, Québec, Canada G1K 7P4

Abbreviations: CVD, Cardiovascular disease; Apo, apolipoprotein; AT, adipose tissue; CT, computed tomography; HOMA, homeostasis model assessment. ies widely depending upon the population studied. Its prevalence can be as high as $37 \%$ in Finns and South Asian immigrants [6, 7]. Determinants of IGT have been the topic of several investigations and include age, obesity (total and central), family history of Type II (non-insulin-dependent) diabetes mellitus, physical inactivity and high triglyceride concentrations [7]. Impaired glucose tolerance is known to be a powerful risk factor for Type II diabetes, with $20-50 \%$ of people with IGT developing Type II diabetes ten years after IGT diagnosis [7].

Subjects with IGT have been shown to be abdominally obese [8-10]. An IGT state has also been associated with alterations in plasma lipid-lipoprotein concentrations [11-14]. Subjects with IGT are therefore 
likely to have many features of the plurimetabolic syndrome resulting from insulin resistance. Prediabetic subjects have been reported to have an atherogenic pattern of metabolic risk factors, characterized by higher concentrations of total and LDL-cholesterol, triglyceride, fasting glucose and insulin, 2-h glucose, higher body mass index (BMI) and blood pressure as well as by lower concentrations of HDL-cholesterol, which can be present for many years before diabetes onset [15]. Thus, this cluster of concomitant metabolic alterations found in IGT could contribute to exacerbate the risk of macrovascular disease as much as the duration of clinical diabetes itself [15]. Accordingly, possibly the presence of the complete plurimetabolic syndrome rather than hyperglycaemia alone largely explains the increased CVD risk in people with IGT, prediabetic and diabetic states.

It is also well documented that some people with excessive visceral adipose tissue (AT), despite a normal glucose tolerance (NGT) state, present numerous complications such as an atherogenic dyslipidaemia, hyperinsulinaemia and hypertension, leading to the development of CVD [16-19]. It is not known whether the metabolic risk profile of viscerally obese people with a NGT differs from those with IGT. Some studies have compared diabetic with non-diabetic subjects with similar BMI to sort out the contribution of obesity to the deterioration in the plasma lipid-lipoprotein profile observed in a diabetic state $[12,20]$. It was found that even after controlling for obesity levels, subjects with diabetes still had higher plasma concentrations of triglycerides and lower HDL-cholesterol concentrations than non-diabetic subjects. It therefore seems that the greater degree of obesity, typical of hyperglycaemic states, does not fully account for the deterioration in the risk profile of hyperglycaemic patients. It is possible that the residual difference in the metabolic profile could be explained by the hyperglycaemic state in itself or by differences in body fat distribution, which are not corrected for when controlling for BMI. The aim of our study was therefore to investigate the contribution of visceral AT, measured by computed tomography (CT), to the deterioration of the metabolic risk profile in subjects with IGT. We studied 284 men with NGT [mean age: $39.4 \pm 11.8$ (SD) years] and 66 men with IGT (47.4 \pm 9.0 years). The two groups were compared before and after a control for their visceral AT accumulation.

\section{Subjects and methods}

Subjects. We recruited 350 men from the Québec City metropolitan area by solicitation through different newspapers between 1987 and 1998. Subjects were between 18 and 68 years of age. Participants were selected to cover a wide range of BMI values $\left(17.9-42.2 \mathrm{~kg} / \mathrm{m}^{2}\right)$. These subjects were tested as part of an ongoing project studying the associations between obesity, body fat distribution and risk factors for Type II diabetes and cardiovascular disease. All subjects were healthy, nonsmoking volunteers and were not receiving treatment for coronary heart disease, diabetes, dyslipidaemias or endocrine disorders. We considered there was IGT with a glycaemia between 7.8 and $11.1 \mathrm{mmol} / \mathrm{l} 2 \mathrm{~h}$ after a $75-\mathrm{g}$ glucose test as recommended by the expert committee on the diagnosis and classification of diabetes mellitus [21]. All participants signed an informed consent document approved by the Laval University Medical Ethics Committee.

Anthropometric measurements. The hydrostatic weighing technique [22] was used to measure body density which was obtained from the mean of six measurements. Pulmonary residual volume was measured before immersion in the hydrostatic tank, using the helium dilution method of Meneely and Kaltreider [23]. The per cent body fat was derived from body density using the equation of Siri [24]. Height, body weight, waist and hip circumferences were measured according to the procedures recommended at the Airlie Conference [25] and the waist-to-hip ratio was calculated.

Computed tomography $(C T)$. Measurements of abdominal AT areas were made by CT with a Siemens Somatom DHR scanner (Erlangen, Germany) as described previously [26]. Briefly, the subjects were examined in the supine position with both arms stretched above the head. The CT scan was done at the abdominal level between L4 and L5 vertebrae, a scout radiograph of the skeleton being used as a reference to establish the position of the scan to the nearest millimetre. Total abdominal AT area was calculated by delineating the abdominal scan with a graph pen and then by computing the AT surface area using an attenuation range of -190 to -30 Hounsfield units. The abdominal visceral AT area was measured by drawing a line within the muscle wall surrounding the abdominal cavity. The abdominal subcutaneous AT area was calculated by subtracting the visceral AT area from the total abdominal AT area.

Plasma lipid-lipoprotein profile. Blood samples were collected from an antecubital vein into vacutainer tubes containing EDTA after a 12-h overnight fast for the measurement of plasma lipid and lipoprotein concentrations. Cholesterol and triglyceride concentrations were measured in plasma and lipoprotein fractions using an analyser Technicon RA-500 (Bayer, Tarry Town, N.Y., USA) and enzymatic reagents were obtained from Randox (Randox Laboratories, Crumlin, UK). Plasma VLDL [density $(\mathrm{d})<1.006 \mathrm{~g} / \mathrm{ml})$ were isolated by ultracentrifugation [27]. The HDL fraction was obtained after precipitation of LDL in the infranatant $(\mathrm{d}>1.006 \mathrm{~g} / \mathrm{ml})$ with heparin and $\mathrm{MnCl}_{2}$ [28]. The cholesterol and triglyceride content of the infranatant were measured before and after the precipitation step. The apolipoprotein (apoB) concentration was measured in plasma and in the LDL fraction by the rocket immuno-electrophoretic method of Laurell [29] as described previously [30]. Lyophilized serum standards for apoB measurements were prepared in our laboratory, calibrated with reference standards obtained from the Centres for Disease Control and Prevention (Atlanta, Ga., USA) and the results validated against external quality controls for apoB [Canadian Reference Laboratory (1996), Vancouver, Canada].

Oral glucose tolerance test (OGTT). A 75-g OGTT was done in the morning after an overnight fast. Blood samples were collected in EDTA-containing tubes (Miles Pharmaceuticals, Rexdale, Ontario, Canada) through a venous catheter placed in an antecubital vein at $-15,0,15,30,45,60,90,120,150$ and 
$180 \mathrm{~min}$ for the measurement of plasma glucose and insulin concentrations. Plasma glucose was measured enzymatically [31], whereas plasma insulin was measured by radioimmunoassay with polyethylene glycol separation [32]. The total glucose and insulin areas under the curve during the OGTT were measured with the trapezoid method.

Variables of insulin-glucose homeostasis. To characterize insulin sensitivity and insulin secretion capacity, we have used the homeostasis model assessment (HOMA model) formula to estimate beta-cell function and insulin resistance as described previously [33]:

Beta-cell function $=(20 \times$ fasting insulin $) /($ fasting glucose 3.5)

Insulin resistance $=($ fasting insulin $\times$ fasting glucose $) / 22.5$

Furthermore, we have used another index of insulin secretion, which evaluates the first phase insulin response and is obtained by computing the following ratio, as suggested previously [34]: $\Delta \mathrm{I}_{30}: \Delta \mathrm{G}_{30}=30$-min increment in plasma insulin concentration over the 30 -min increment in plasma glucose concentration in an OGTT.

Statistical analyses. An unpaired Student $t$ test was done to compare men with NGT and men with IGT. Covariance analysis was used to evaluate the effect of age and visceral AT accumulation on the differences found in the metabolic risk profile between men with NGT and men with IGT. The group of men with NGT was then divided on the basis of BMI $\left(<25 \mathrm{~kg} / \mathrm{m}^{2}\right.$ (control group) or $\geq 25 \mathrm{~kg} / \mathrm{m}^{2}$ ). The group of men with NGT and a BMI of $25 \mathrm{~kg} / \mathrm{m}^{2}$ or more was also further divided into two subgroups according to their visceral AT areas: BMI of 25 $\mathrm{kg} / \mathrm{m}^{2}$ or more with low visceral AT accumulation and BMI of $25 \mathrm{~kg} / \mathrm{m}^{2}$ or more with high visceral AT accumulation. For similar fat mass between the NGT with low visceral AT, NGT with high visceral AT and men with IGT, these groups were paired for fat mass on a group basis. Comparisons among subgroups were done by analysis of variance using the general linear model and the Duncan post hoc test was used in situations where a statistically significant group effect was observed. Pearson correlation coefficients were computed to quantify the associations among variables. The chi-squared test was used to compare: firstly the prevalence of high visceral AT area $\left(\geq 130 \mathrm{~cm}^{2}\right)$ between men with NGT and men with IGT and secondly the prevalence of IGT between men with low visceral AT area $\left(<130 \mathrm{~cm}^{2}\right)$ and men with high visceral AT area $\left(\geq 130 \mathrm{~cm}^{2}\right)$. Some variables were not normally distributed (HDL-cholesterol, $\mathrm{HDL}_{2}$-cholesterol, triglycerides and apolipoprotein AI). For these variables, analyses were done on their log-transformed values. All these analyses were done on the SAS statistical package (SAS Institute, Cary, N.C., USA).

\section{Results}

Subjects with IGT were characterized by increased adiposity as they have higher BMI, body fat mass, waist circumference, waist-to-hip ratio as well as higher total abdominal and visceral AT areas than subjects characterized by NGT $(p<0.0001)$ (Table 1). We calculated the prevalence of IGT among subjects with high visceral AT $\left(\geq 130 \mathrm{~cm}^{2}\right)$, a threshold value above which a greater likelihood of finding the cluster of metabolic abnormalities of the insulin
Table 1. Physical characteristics of men with NGT and men with IGT

\begin{tabular}{lcc}
\hline & $\begin{array}{l}\text { Men with NGT } \\
(n=284)\end{array}$ & $\begin{array}{l}\text { Men with IGT } \\
(n=66)\end{array}$ \\
\hline Age (years) & $39.4 \pm 11.8$ & $47.4 \pm 9.0^{\mathrm{a}}$ \\
BMI $\left(\mathrm{kg} / \mathrm{m}^{2}\right)$ & $27.4 \pm 4.6$ & $30.9 \pm 4.2^{\mathrm{a}}$ \\
Body fat masss $(\mathrm{kg})$ & $21.3 \pm 9.7$ & $29.6 \pm 8.9^{\mathrm{a}}$ \\
Waist circumference $(\mathrm{cm})$ & $93.9 \pm 12.4$ & $105.2 \pm 10.5^{\mathrm{a}}$ \\
Waist-to-hip ratio & $0.92 \pm 0.07$ & $0.99 \pm 0.05^{\mathrm{a}}$ \\
CTabdominal AT areas $\left(\mathrm{cm}^{2}\right)$ & & \\
$\quad$ Total & $365.0 \pm 175.6$ & $516 \pm 151.1^{\mathrm{a}}$ \\
$\quad$ Visceral & $124.7 \pm 63.9$ & $190.6 \pm 66.0^{\mathrm{a}}$ \\
$\quad$ Subcutaneous & $240.3 \pm 127.9$ & $326.2 \pm 11.3^{\mathrm{a}}$ \\
\hline
\end{tabular}

${ }^{a}$ significant difference between men with NGT vs men with IGT $p<0.0001$

resistance dyslipidaemic syndrome has been reported $[35,36]$. We found that $32.6 \%$ of subjects with high visceral AT accumulation were characterized by IGT. This prevalence was higher than the $5.1 \%$ prevalence found among men with a low visceral AT accumulation $\left(<130 \mathrm{~cm}^{2}\right)(p<0.001)$. We have also calculated within the group of men with IGT, the prevalence of men with high compared with low visceral AT accumulation. We found that $86.4 \%$ of men with IGT had a visceral AT area above $130 \mathrm{~cm}^{2}$ compared with only a $41.6 \%$ prevalence of increased visceral AT among men with NGT $(p<0.001)$ (Fig. 1$)$.

As expected, fasting glucose, glucose area under the curve and 2-h post-OGTT glucose concentrations were higher in men with IGT than in men with NGT $(p<0.0001)$ (Table 2). Plasma insulin concentrations measured in the fasting state and after glucose ingestion as well as indicators of insulin resistance and beta-cell function, determined using the HOMA model, were also found to be higher in men with IGT $(p<0.02)$ than in men with NGT. Furthermore, fasting plasma concentrations of total cholesterol, triglycerides, LDL-cholesterol, apoB and LDL-apoB, as well as the total cholesterol:HDL-cholesterol ratio were significantly higher whereas HDL-cholesterol and $\mathrm{HDL}_{2}$-cholesterol concentrations were significantly lower in men with IGT than in men characterized by NGT $(p<0.02)$. No significant differences were, however, found between the two groups for $\Delta \mathrm{I}_{30}: \Delta \mathrm{G}_{30}$ ratio and for the concentrations of $\mathrm{HDL}_{3}$-cholesterol and apoAI.

As subjects with IGT were statistically significantly older than men characterized by a NGT, we did an adjustment for age, which failed to alter differences noted with the exception of plasma concentrations of total cholesterol and LDL-cholesterol which were no longer statistically different between the two groups (data not shown).

As expected, when univariate correlation coefficients were computed, we found that increased body fat mass and visceral AT area were associated with al- 

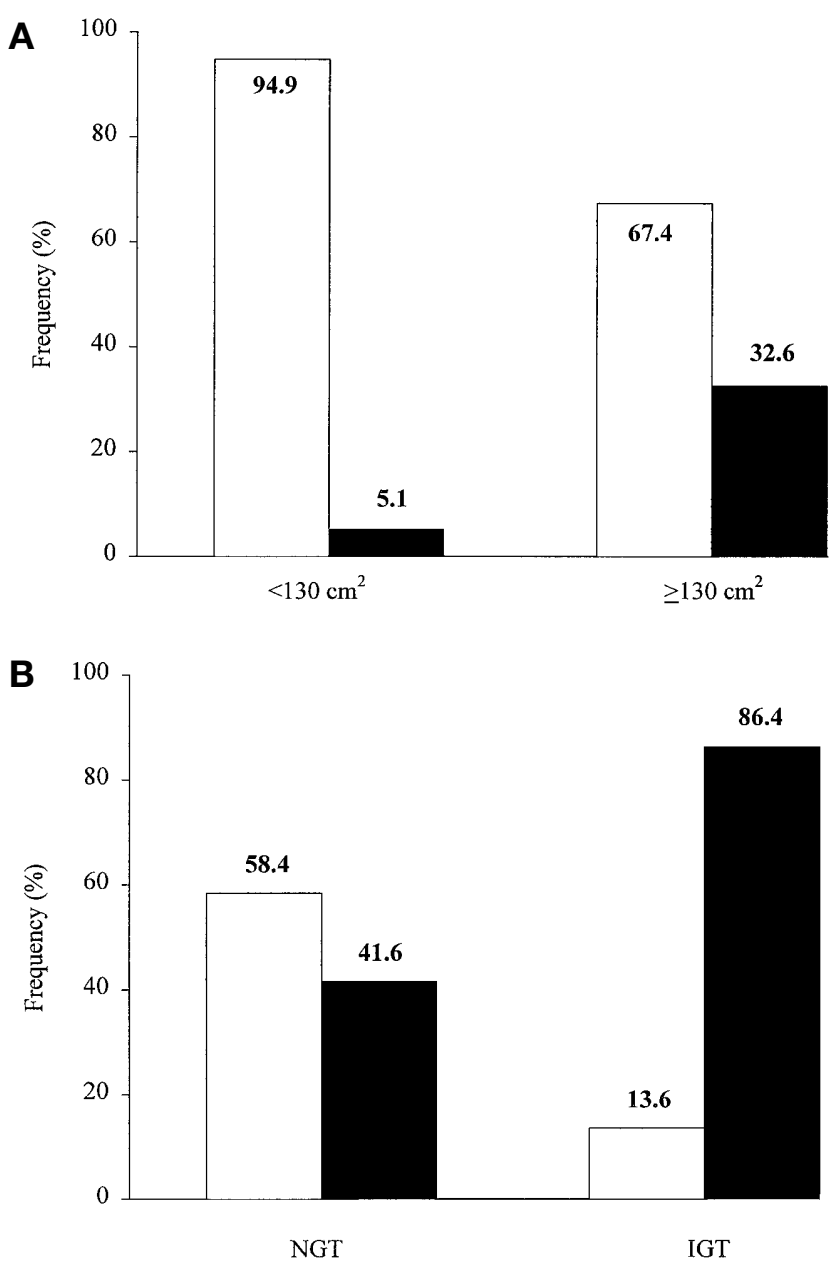

Fig. 1. A Prevalence of normal glucose tolerance (NGT, $\square$ ) and impaired glucose tolerance (IGT, $\square$ ) states in subjects with low and high visceral adipose tissue (AT) accumulation. Significant difference between men with low vs men with high visceral AT $p<0.001$. B Prevalence of low $\left(\square<130 \mathrm{~cm}^{2}\right)$ and high $\left(\square \geq 130 \mathrm{~cm}^{2}\right)$ visceral AT accumulation in subjects either characterized by NGT and IGT. Significant difference between men with NGT vs men with IGT $p<0.001$

tered indices of insulin-glucose homeostasis in the total group of men. Visceral AT was significantly related to fasting insulin $(r=0.55, p<0.0001)$, fasting glucose $(r=0.41, p<0.0001)$, areas under the curve of insulin $(r=0.57, p<0.0001)$ and glucose $(r=0.53$, $p<0.0001)$ and the $\Delta \mathrm{I}_{30}: \Delta \mathrm{G}_{30}$ ratio $(r=0.24$, $p<0.0001)$. Furthermore, increased amounts of visceral AT were also associated with altered lipoprotein-lipid profiles. Plasma lipid and lipoprotein values varied according to visceral AT accumulation, irrespective of glucose tolerance status (Fig. 2).

We did covariance analysis to investigate the contribution of visceral AT area to the differences in the lipid-lipoprotein variables found between men with NGT and men with IGT (Tables 3, 4). After such an adjustment for visceral AT, body fat mass was similar between the two groups (Table 3 ). None of the differences in the indices of plasma insulin-glucose homeo-
Table 2. Metabolic risk profile of men with NGT and men with IGT

\begin{tabular}{|c|c|c|}
\hline & $\begin{array}{l}\text { Men with NGT } \\
\quad(n=284)\end{array}$ & $\begin{array}{l}\text { Men with IGT } \\
\quad(n=66)\end{array}$ \\
\hline \multicolumn{3}{|l|}{ Insulin-glucose homeostasis } \\
\hline Fasting glucose $(\mathrm{mmol} / \mathrm{l})$ & $5.18 \pm 0.39$ & $5.72 \pm 0.58^{a}$ \\
\hline Fasting insulin ( $\mathrm{pmol} / \mathrm{l})$ & $72.5 \pm 47.1$ & $120.0 \pm 71.7^{\mathrm{a}}$ \\
\hline Glucose area $\left(\times 10^{-3} \mathrm{mmol} / \mathrm{l}\right)$ & $1.14 \pm 0.18$ & $1.58 \pm 0.14^{\mathrm{a}}$ \\
\hline Insulin area $\left(\times 10^{-3} \mathrm{pmol} / \mathrm{l}\right)$ & $82.6 \pm 57.5$ & $145.4 \pm 84.7^{\mathrm{a}}$ \\
\hline Insulin resistance & $16.9 \pm 11.2$ & $30.6 \pm 18.6^{\mathrm{a}}$ \\
\hline Beta-cell function & $883.0 \pm 706.2$ & $1132.2 \pm 747.2^{\mathrm{b}}$ \\
\hline$\Delta \mathrm{I}_{30}: \Delta \mathrm{G}_{30}$ & $175.9 \pm 128.3$ & $152.1 \pm 93.6$ \\
\hline 2-h post-OGTT glucose & $5.61 \pm 1.14$ & $8.89 \pm 0.70^{\mathrm{a}}$ \\
\hline \multicolumn{3}{|l|}{ Lipid-lipoprotein profile } \\
\hline Cholesterol $(\mathrm{mmol} / \mathrm{l})$ & $5.08 \pm 0.88$ & $5.54 \pm 0.72^{\mathrm{a}}$ \\
\hline Triglycerides $(\mathrm{mmol} / \mathrm{l})$ & $1.76 \pm 1.01$ & $2.34 \pm 1.11^{\mathrm{a}}$ \\
\hline LDL-chol $(\mathrm{mmol} / \mathrm{l})$ & $3.45 \pm 0.80$ & $3.77 \pm 0.74^{\mathrm{b}}$ \\
\hline HDL-chol (mmol/1) & $0.99 \pm 0.23$ & $0.94 \pm 0.19^{\mathrm{b}}$ \\
\hline $\mathrm{HDL}_{2}-\mathrm{chol}(\mathrm{mmol} / \mathrm{l})$ & $0.32 \pm 0.17$ & $0.26 \pm 0.14^{\mathrm{c}}$ \\
\hline $\mathrm{HDL}_{3}-\operatorname{chol}(\mathrm{mmol} / \mathrm{l})$ & $0.67 \pm 0.13$ & $0.67 \pm 0.11$ \\
\hline Chol/HDL-chol & $5.38 \pm 1.51$ & $6.14 \pm 1.28^{\mathrm{a}}$ \\
\hline $\operatorname{ApoB}(g / 1)$ & $1.02 \pm 0.24$ & $1.16 \pm 0.19^{\mathrm{a}}$ \\
\hline LDL-apoB (g/l) & $0.91 \pm 0.21$ & $1.03 \pm 0.17^{\mathrm{a}}$ \\
\hline $\operatorname{ApoAI}(g / 1)$ & $1.19 \pm 0.18$ & $1.21 \pm 0.17$ \\
\hline
\end{tabular}

Chol $=$ cholesterol. Insulin resistance from HOMA model $=$ (fasting insulin $\times$ fasting glucose)/22.5. Beta-cell function from HOMA model $=(20 \times$ fasting insulin $) /($ fasting glucose -3.5). $\Delta \mathrm{I}_{30}: \Delta \mathrm{G}_{30}=$ insulin-glucose (0-30 min) ratio

${ }^{a}$ significant difference between men with NGT vs men with IGT $p<0.0005,{ }^{\mathrm{b}} p<0.02,{ }^{\mathrm{c}} p<0.001$

Table 3. Physical characteristics of men with NGT and men with IGT after adjustment for the area of visceral AT

\begin{tabular}{lcc}
\hline & $\begin{array}{c}\text { Men with NGT } \\
(n=284)\end{array}$ & $\begin{array}{c}\text { Men with IGT } \\
(n=66)\end{array}$ \\
\hline Age (years) & $40.3 \pm 10.4$ & $43.3 \pm 10.9^{\mathrm{a}}$ \\
BMI $\left(\mathrm{kg} / \mathrm{m}^{2}\right)$ & $28.0 \pm 3.1$ & $28.1 \pm 3.3$ \\
Body fat mass $(\mathrm{kg})$ & $22.6 \pm 6.7$ & $23.9 \pm 7.1$ \\
Waist circumference $(\mathrm{cm})$ & $95.7 \pm 7.7$ & $97.3 \pm 8.0$ \\
Waist-to-hip ratio & $0.93 \pm 0.05$ & $0.95 \pm 0.05^{\mathrm{a}}$ \\
CTabdominal ATareas $\left(\mathrm{cm}^{2}\right)$ & & \\
$\quad$ Total & $391.8 \pm 101.9$ & $401.4 \pm 106.7$ \\
$\quad$ Visceral & 137.1 & 137.1 \\
$\quad$ Subcutaneous & $254.7 \pm 101.9$ & $264.2 \pm 106.7$ \\
\hline a significant difference between men with NGT vs men with \\
IGT $p<0.05$
\end{tabular}

stasis were, however, eliminated (Table 4), whereas differences initially found in plasma triglycerides, apoB, LDL-apoB, total cholesterol:HDL-cholesterol ratio, $\mathrm{HDL}$-cholesterol and $\mathrm{HDL}_{2}$-cholesterol were no longer observed after adjustment for visceral AT area.

We divided the group of men with NGT into three subgroups to sort out the contribution of body fat and visceral AT to the metabolic deterioration observed in men with IGT. The first subgroup was men with a BMI less than $25 \mathrm{~kg} / \mathrm{m}^{2}$ (non-obese controls). The second subgroup was composed of men with a BMI 

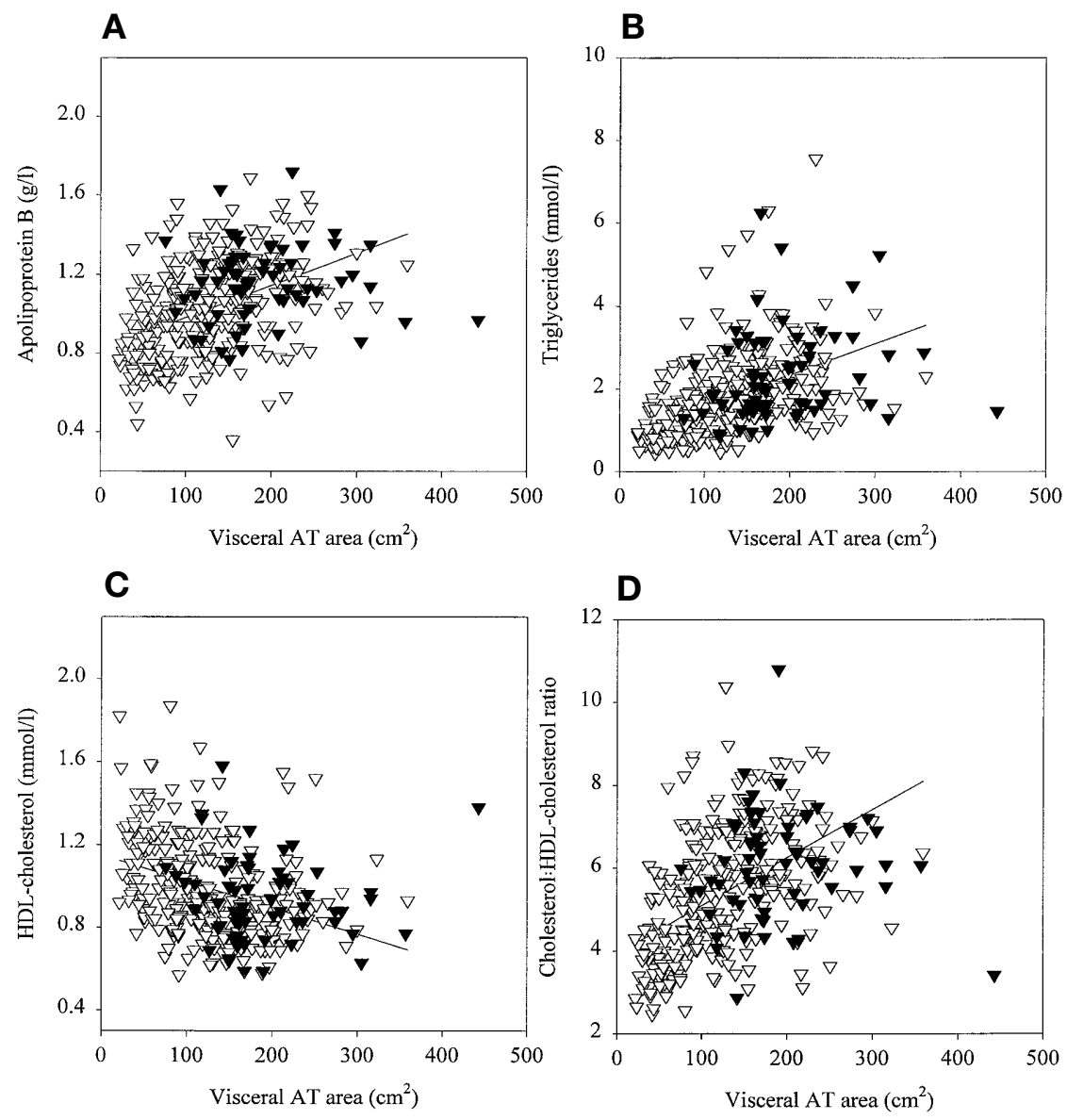

Fig. 2. Relationships between visceral AT area and plasma levels of apolipoprotein B $(\mathbf{A}, r=0.42, p<0.0001)$, triglyceride (B, $r=0.46, \quad p<0.0001)$, HDL-cholesterol (C, $r=-0.32$, $p<0.0001)$ and the ratio of cholesterol:HDL-cholesterol (D, $r=0.45, p<0.0001)$. $\nabla$ NGT $(n=284), \nabla \operatorname{IGT}(n=66)$

of $25 \mathrm{~kg} / \mathrm{m}^{2}$ or more but with a low visceral AT accumulation. The third subgroup was men with a BMI of $25 \mathrm{~kg} / \mathrm{m}^{2}$ or more and a high visceral AT accumulation. Groups were matched for fat mass on a group basis to have similar body fat mass in the two groups of overweight men with NGT and in the group of men with IGT. As expected, the two groups of overweight men with NGT and men with IGT were characterized by similar amounts of fat mass but these three subgroups showed significantly higher fat mass compared with the control group (Table 5). Furthermore, visceral obese men with NGT and men with IGT showed a similar excess of visceral AT. Indices of insulin-glucose homeostasis as well as variables of the lipid-lipoprotein profile of men with IGT were significantly different from control men with the exception of the ratio of $\Delta \mathrm{I}_{30}: \Delta \mathrm{G}_{30}$ as well as of $\mathrm{HDL}_{3}$-cholesterol and apoAI concentrations (Table 6). Significant differences in total cholesterol, triglyceride, apoB and LDL-apoB concentrations as

well as in the cholesterol:HDL-cholesterol ratio and in all indicators of insulin-glucose homeostasis (except beta-cell function) were observed between men with IGT and men characterized by NGT and low amounts of visceral AT. Finally, despite statistically significant differences in indices of insulin-glucose homeostasis (except beta-cell function), no difference in the plasma lipid-lipoprotein profile was observed between men with IGT and men with NGT and high amounts of visceral AT. It is also important to note that for the same amount of visceral AT and fat mass, and for a similar age, men with NGT and men with IGT were not different in their plasma lipoprotein profile although there were important differences in variables related to their insulin-glucose homeostasis.

\section{Discussion}

Type II diabetes is a metabolically heterogeneous condition and is invariably preceded by IGT [37]. In this sense, IGT is not recognized as a disease in itself but rather as a risk for future development of diabetes $[38,39]$, despite that IGT can also be a marker of CVD risk [40, 41]. Type II diabetes and IGT are associated with an increased CVD risk [1-6, 42-45]. Some recent studies have, however, suggested that the pri- 
Table 4. Metabolic risk profile of men with NGT and men with IGT after adjustment for the area of visceral AT

\begin{tabular}{|c|c|c|}
\hline & $\begin{array}{l}\text { Men with NGT } \\
\quad(n=284)\end{array}$ & $\begin{array}{l}\text { Men with IGT } \\
\quad(n=66)\end{array}$ \\
\hline \multicolumn{3}{|l|}{ Insulin-glucose homeostasis } \\
\hline Fasting glucose $(\mathrm{mmol} / \mathrm{l})$ & $5.21 \pm 0.42$ & $5.61 \pm 0.44^{\mathrm{a}}$ \\
\hline Fasting insulin $(\mathrm{pmol} / \mathrm{l})$ & $77.4 \pm 46.5$ & $98.7 \pm 48.7^{\mathrm{b}}$ \\
\hline Glucose area $\left(\times 10^{-3} \mathrm{mmol} / \mathrm{l}\right)$ & $1.15 \pm 0.15$ & $1.53 \pm 0.16^{\mathrm{a}}$ \\
\hline Insulin area $\left(\times 10^{-3} \mathrm{pmol} / \mathrm{l}\right)$ & $88.7 \pm 56.1$ & $119.9 \pm 58.7^{\mathrm{c}}$ \\
\hline Insulin resistance & $18.1 \pm 11.3$ & $25.3 \pm 11.9^{\mathrm{a}}$ \\
\hline Beta-cell function & $926.2 \pm 686.6$ & $947.0 \pm 719.2$ \\
\hline$\Delta \mathrm{I}_{30}: \Delta \mathrm{G}_{30}$ & $182.7 \pm 119.0$ & $122.7 \pm 124.8^{c}$ \\
\hline 2-h post-OGTT glucose & $5.68 \pm 1.07$ & $8.57 \pm 1.12^{\mathrm{a}}$ \\
\hline \multicolumn{3}{|l|}{ Lipid-lipoprotein profile } \\
\hline Cholesterol (mmol/l) & $5.12 \pm 0.83$ & $5.32 \pm 0.87$ \\
\hline Triglycerides $(\mathrm{mmol} / \mathrm{l})$ & $1.85 \pm 0.95$ & $1.98 \pm 0.99$ \\
\hline LDL-chol (mmol/l) & $3.48 \pm 0.79$ & $3.63 \pm 0.82$ \\
\hline HDL-chol (mmol/l) & $0.98 \pm 0.21$ & $0.99 \pm 0.22$ \\
\hline $\mathrm{HDL}_{2}$-chol $(\mathrm{mmol} / \mathrm{l})$ & $0.31 \pm 0.16$ & $0.31 \pm 0.17$ \\
\hline $\mathrm{HDL}_{3}$-chol $(\mathrm{mmol} / \mathrm{l})$ & $0.67 \pm 0.13$ & $0.68 \pm 0.13$ \\
\hline Chol/HDL-chol & $5.50 \pm 1.36$ & $5.64 \pm 1.43$ \\
\hline ApoB (g/l) & $1.04 \pm 0.22$ & $1.09 \pm 0.23$ \\
\hline LDL-apoB (g/l) & $0.92 \pm 0.20$ & $0.97 \pm 0.21$ \\
\hline $\operatorname{ApoAI}(\mathrm{g} / \mathrm{l})$ & $1.19 \pm 0.18$ & $1.21 \pm 0.19$ \\
\hline
\end{tabular}

Chol $=$ cholesterol. Insulin resistance from HOMA model $=$ (fasting insulin $\times$ fasting glucose)/22.5. Beta-cell function from HOMA model $=(20 \times$ fasting insulin $) /($ fasting glucose -3.5). $\Delta \mathrm{I}_{30}: \Delta \mathrm{G}_{30}=$ insulin-glucose (0-30 min) ratio

${ }^{a}$ significant difference between men with NGT vs men with IGT $p<0.0001,{ }^{\mathrm{b}} p<0.001,{ }^{\mathrm{c}} p<0.0005$

mary cause of macrovascular damage is not necessarily hyperglycaemia $[4,46]$. It has therefore been proposed that other factors must be involved to explain the increased CVD risk in hyperglycaemic states. A recent study has reported that the prevalence of peripheral arterial disease was greater in subjects with diabetes or IGT than subjects characterized by a NGT. After adjusting for either systolic blood pressure or plasma triglycerides, subjects with diabetes or IGT no longer had a statistically significant higher risk of peripheral arterial disease than subjects with NGT [46]. The authors concluded that increased mean concentrations of triglycerides and systolic blood pressure could help to explain the higher prevalence of peripheral arterial disease in diabetic and IGT subjects than those having a NGT. Although a dyslipidaemic state is frequently found in Type II diabetic patients and in subjects characterized by IGT, it is also typically found among patients with visceral obesity who have NGT [16-19, 47]. More specifically, it has been reported that people with high amounts of visceral AT are characterized by numerous deteriorations of their lipid-lipoprotein profile $[10,16,18$, 48-50]. Insulin resistance is also a common feature of visceral obesity $[19,35,51,52]$. In this study, we have shown that IGT had a high prevalence among visceral obese men as $33 \%$ of men with a visceral AT accumulation equal or greater than $130 \mathrm{~cm}^{2}$ were characterized by IGT.

Subjects with IGT are frequently characterized by high adiposity and especially by an increased accumulation of visceral AT [8-10]. Our results are in agreement with these previous findings as IGT men were characterized by visceral obesity compared with men with NGT. Furthermore, as previously reported [11-14], we have shown that subjects with IGT were characterized by a deteriorated lipid-lipoprotein profile compared with men with NGT.

The main objective of our study was to verify whether the increased visceral AT accumulation found in men with IGT could explain the presence of an altered lipid-lipoprotein profile. When we adjusted for differences in visceral AT by covariance analysis, all differences in the lipid-lipoprotein profile observed between men with NGT and men with IGT were eliminated. As the adjustment for visceral AT accumulation also eliminated differences in body fat mass between the two groups, we then compared

Table 5. Physical characteristics of the IGT and NGT men divided on the basis of BMI and visceral AT (VAT) areas

\begin{tabular}{|c|c|c|c|c|}
\hline & \multicolumn{3}{|c|}{ NGT } & \multirow{3}{*}{$\begin{array}{l}\text { IGT } \\
(n=57)\end{array}$} \\
\hline & \multirow{2}{*}{$\begin{array}{l}\mathrm{BMI}<25 \\
(n=94)\end{array}$} & \multicolumn{2}{|c|}{$\mathrm{BMI} \geq 25$} & \\
\hline & & $\begin{array}{l}\text { low VAT } \\
(n=58)\end{array}$ & $\begin{array}{l}\text { high VAT } \\
(n=64)\end{array}$ & \\
\hline Age (years) & $35.0 \pm 12.2$ & $35.4 \pm 8.2$ & $44.2 \pm 7,5^{\mathrm{a}, \mathrm{b}}$ & $47.0 \pm 9.1^{\mathrm{a}, \mathrm{b}}$ \\
\hline $\operatorname{BMI}\left(\mathrm{kg} / \mathrm{m}^{2}\right)$ & $22.5 \pm 1.7$ & $30.1 \pm 3.4^{\mathrm{a}}$ & $30.9 \pm 3.3^{\mathrm{a}}$ & $30.9 \pm 3.2^{\mathrm{a}}$ \\
\hline Body fat mass (kg) & $11.9 \pm 5.0$ & $27.8 \pm 7.2^{\mathrm{a}}$ & $28.0 \pm 7.0^{\mathrm{a}}$ & $29.7 \pm 7.7^{\mathrm{a}}$ \\
\hline Waist-to-hip ratio & $0.86 \pm 0.05$ & $0.94 \pm 0.05^{\mathrm{a}}$ & $0.98 \pm 0.05^{\mathrm{a}, \mathrm{b}}$ & $0.99 \pm 0.04^{\mathrm{a}, \mathrm{b}}$ \\
\hline \multicolumn{5}{|l|}{ CT abdominal AT areas $\left(\mathrm{cm}^{2}\right)$} \\
\hline Total & $190.5 \pm 84.6$ & $455.7 \pm 127.9^{\mathrm{a}}$ & $510.1 \pm 117.8^{\mathrm{a}, \mathrm{b}}$ & $520.0 \pm 130.5^{\mathrm{a}, \mathrm{b}}$ \\
\hline Visceral & $69.5 \pm 33.9$ & $115.7 \pm 29.7^{\mathrm{a}}$ & $194.0 \pm 32.4^{\mathrm{a}, \mathrm{b}}$ & $186.0 \pm 53.1^{\mathrm{a}, \mathrm{b}}$ \\
\hline Subcutaneous & $121.1 \pm 58.7$ & $340.1 \pm 111.6^{\mathrm{a}}$ & $316.2 \pm 102.1^{\mathrm{a}}$ & $334.1 \pm 102.4^{\mathrm{a}}$ \\
\hline
\end{tabular}

${ }^{\mathrm{a}}$ significantly different from NGT men with BMI $<25, p<0.0001 ;{ }^{\mathrm{b}}$ significantly different from NGT men with BMI $\geq 25$ and low VAT, $p<0.0001$ 
Table 6. Metabolic risk profile of the IGT and NGT men divided on the basis of BMI and visceral AT (VAT) areas

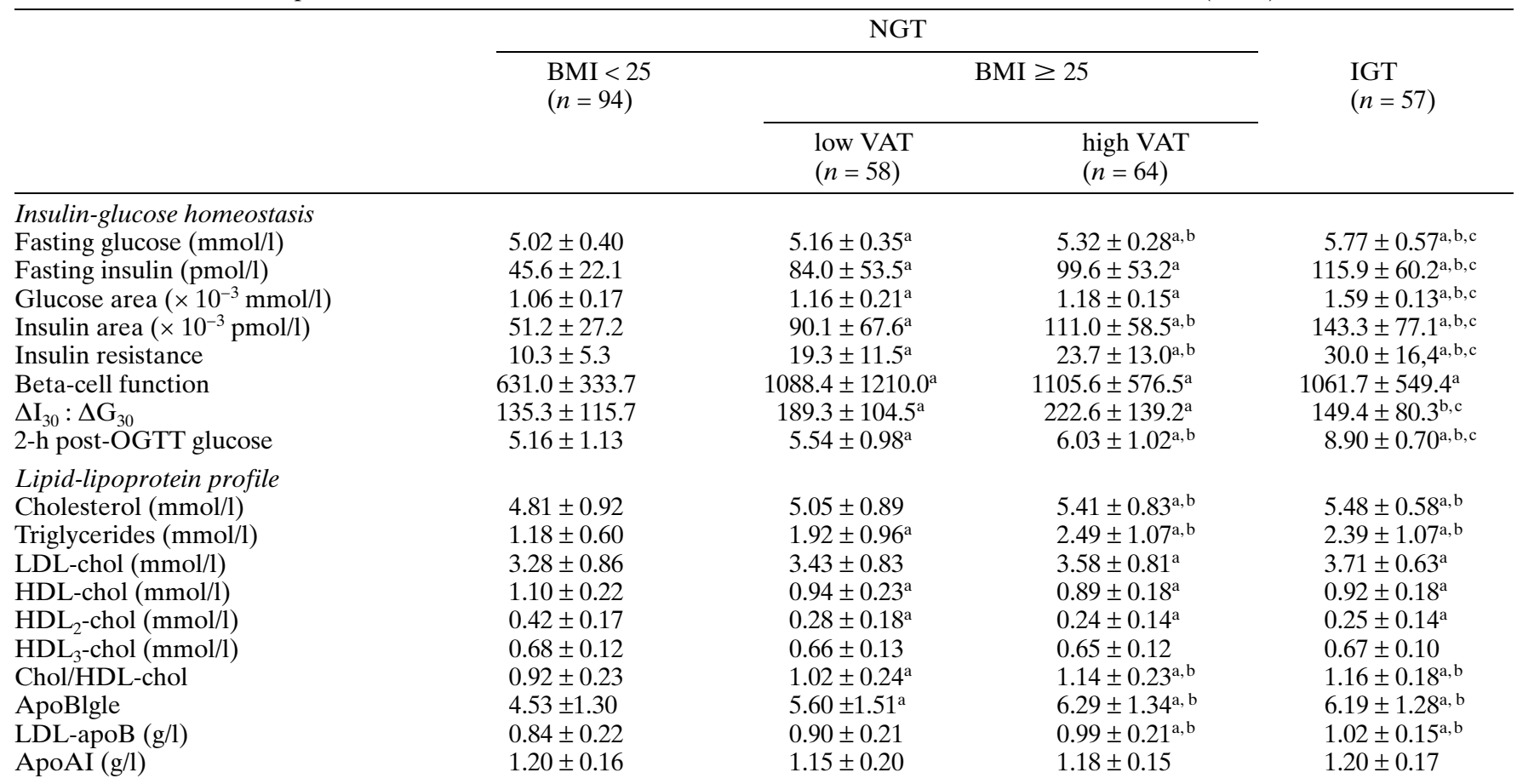

Chol $=$ cholesterol. $\quad$ Insulin resistance $=($ fasting insulin $\times$ fasting glucose $) / 22.5$, beta-cell function $=(20 \times$ fasting insulin)/(fasting glucose -3.5), $\Delta \mathrm{I}_{30}: \Delta \mathrm{G}_{30}=$ insulin-glucose (0-30 min) ratio; ${ }^{a}$ significantly different from NGT men with
$\mathrm{BMI}<25, p<0.01,{ }^{\mathrm{b}}$ significantly different from NGT men with $\mathrm{BMI} \geq 25$ and low VAT, $p<0.01$, ${ }^{\mathrm{c}}$ significantly different from NGT men with BMI $\geq 25$ and high VAT, $p<0.01$ four groups of men formed on the basis of visceral AT area and fat mass. This comparison allowed the proper study of the contribution of visceral AT area and fat mass to the deterioration of the lipid-lipoprotein profile.

Our results suggest that, over the range of glycaemia found in our subjects with IGT, high amounts of visceral AT contributed more to the deterioration of the plasma lipid-lipoprotein profile than circulating glucose concentrations. As mentioned above, after adjustment for the amounts of visceral AT, all differences initially found in the lipid-lipoprotein profile between men with IGT and men with NGT were eliminated despite fasting glucose and 2-h postOGTT glucose concentrations remaining significantly higher in men with IGT. Our results provide new information adding to an earlier report [12] that differences in obesity (as estimated by the BMI) were not sufficient to explain differences in lipid-lipoprotein profile suggesting that hyperglycaemia in itself explains the residual differences in lipid-lipoprotein profile between subjects with NGT and subjects with IGT. Our study suggests that control for visceral AT is a more powerful approach than adjustment for BMI to explain the deteriorated plasma lipoprotein profile of men with IGT.

The comparison of the four subgroups showed that fat mass in itself could make a trivial contribution to the deterioration of the lipid profile found in men with IGT compared with men characterized by a NGT. For instance, when we compared a group of men with NGT with low visceral AT accumulation but with a similar body fat mass to men with IGT, no difference in LDL-cholesterol as well as in HDL-cholesterol and $\mathrm{HDL}_{2}$-cholesterol were observed. An increased fat mass alone is therefore not sufficient to explain most of the differences found in the lipoprotein profile between men with NGT and men with IGT. Men with a high fat mass but with a low accumulation of visceral AT had statistically significantly lower levels of cholesterol, triglycerides, apoB, LDL-apoB as well as lower cholesterol:HDL-cholesterol ratios than men with a high visceral AT accumulation (either characterized by NGT or IGT), all these factors being recognized as important correlates of the CVD risk [53]. Men with NGT matched with men with IGT for fat mass and showing similar amounts of visceral AT to them, had, however, a lipid-lipoprotein profile which was similar to men with IGT, clearly showing the important contribution of visceral AT to the deterioration of the lipid-lipoprotein profile observed in men with IGT.

Thus, viscerally obese men with NGT had a deterioration of their lipid-lipoprotein profile similar to men with IGT despite remaining differences in indices of insulin secretion and insulin resistance. For 
the same level of visceral fat, men with IGT were characterized by a substantially lower $\Delta \mathrm{I}_{30}: \Delta \mathrm{G}_{30}$ ratio than subjects with NGT, suggesting that the decreased early insulin secretion in men with IGT is probably mediated by additional factors more specific to the IGT state itself. In addition, for similar amounts of abdominal visceral AT, subjects with IGT continued to show higher concentrations of plasma insulin than men with NGT but both groups became similar for their lipid-lipoprotein profile. This suggests that, in this study, the deteriorated lipid-lipoprotein profile observed in men with IGT was more closely the result of a concomitant increase in visceral AT than of higher circulating insulin concentrations. We have to acknowledge that although plasma insulin concentration is a fair marker of insulin resistance in NGT states, the relation between insulin concentration and insulin resistance is different and weaker in IGT states. In other words, it is possible that a given concentration of plasma insulin does not reflect the same degree of insulin resistance in NGT compared with IGT people. The interpretation of our results for the respective contribution of visceral AT and insulin resistance to the deterioration of the plasma lipid-lipoprotein profile found in men with IGT are limited because we did not directly assess insulin resistance.

In our study, visceral AT appeared as an important contributor to the deterioration of the plasma lipid-lipoprotein profile observed in subjects with IGT. It is known that IGT can be reversed by physical activity on a regular basis, by using an appropriate diet or symptomatically by a pharmaceutical agent for treatment $[54,55]$. In subjects with IGT, an improvement in glucose homeostasis is desirable but it should also be accompanied by an improved lipid-lipoprotein profile to substantially reduce CVD risk. We believe that weight loss, which is known to be associated with a preferential visceral AT loss among people with high amounts of visceral AT [56], can contribute considerably to the improvement of the lipid-lipoprotein profile. A recent study has shown that reduction in central abdominal fat (but not other body fat compartments) was associated with an improvement in the lipid profile, independently of Type II diabetes, suggesting that visceral abdominal fat loss is specifically related to such improvements [57]. Furthermore, visceral fat has been shown to be the most relevant factor for metabolic abnormalities and the effect of visceral AT on these variables to be independent of BMI [50]. Finally, we believe that it is important to identify people with IGT to prevent further aggravation of their hyperglycaemia and dyslipidaemia. We found, however, that men with NGT with amounts of visceral AT similar to men with IGT had a similar deterioration in their lipid-lipoprotein profile. It seems, therefore, that the identification of subjects with a high accumulation of visceral AT, irrespectively of their glucose tolerance status, is critical. Accordingly, it has been suggested that the measurement of waist girth might be a good tool to identify subjects with high visceral AT accumulation [58].

Our results suggest that, in subjects with IGT, the increased visceral AT depot is a predominant factor in the deterioration of the lipid-lipoprotein profile.

Acknowledgements. The authors would like to express their gratitude to the subjects for their excellent collaboration and to the staff of the Lipid Research Center and the Physical Activity Sciences Laboratory for their contribution to this study. We especially want to thank Ms L. Allard, S. Brulotte, L. Bargone and Mr G. Fournier, H. Bessette and C. Leblanc for their help in the collection and analysis of the data. The study was supported by the Canadian Diabetes Association and by the Medical Research Council of Canada. I. Lemieux is a recipient of a student scholarship from the Heart and Stroke Foundation of Canada, J. Bergeron is a clinical research scholar from the Quebec Funds for Health Research (FRSQ) and S. Lemieux is a research scholar from the Medical Research Council of Canada.

\section{References}

1. Smith GD, Egger M, Shipley MJ, Marmot MG (1992) Postchallenge glucose concentration, impaired glucose tolerance, diabetes, and cancer mortality in men. Am J Epidemiol 136: 1110-1114

2. Jarrett RJ, McCartney P, Keen H (1982) The Bedford survey: ten year mortality rates in newly diagnosed diabetics, borderline diabetics and normoglycaemic controls and risk indices for coronary heart disease in borderline diabetics. Diabetologia 22: 79-84

3. Fuller JH, Shipley MJ, Rose G, Jarrett RJ, Keen H (1983) Mortality from coronary heart disease and stroke in relation to degree of glycaemia: the Whitehall study. BMJ 287: $867-870$

4. Tominaga M, Eguchi H, Manaka H, Igarashi K, Kato T, Sekikawa A (1999) Impaired glucose tolerance is a risk factor for cardiovascular disease, but not impaired fasting glucose. The Funagata diabetes study. Diabetes Care 22: 920-924

5. Knowler WC, Sartor G, Melander A, Schersten B (1997) Glucose tolerance and mortality, including a substudy of tolbutamide treatment. Diabetologia 40: 680-686

6. Stengard JH, Tuomilehto J, Pekkanen J et al. (1992) Diabetes mellitus, impaired glucose tolerance and mortality among elderly men: the Finnish cohorts of the Seven Countries Study. Diabetologia 35: 760-765

7. Alberti KG (1998) Impaired glucose tolerance: what are the clinical implications? Diabetes Res Clin Pract 40 [Suppl]: S3-S8

8. Kawamoto T, Ishikawa K (1996) Intra-abdominal fat, lipid metabolism and insulin resistance in coronary artery disease. Hypertens Res 19 [Suppl 1]: S69-S74

9. Ronnemaa T, Koskenvuo M, Marniemi J et al. (1997) Glucose metabolism in identical twins discordant for obesity. The critical role of visceral fat. J Clin Endocrinol Metab 82: 383-387

10. Fujioka S, Matsuzawa Y, Tokunaga K, Tarui S (1987) Contribution of intra-abdominal fat accumulation to the impairment of glucose and lipid metabolism in human obesity. Metabolism 36: 54-59 
11. Watanabe N, Taniguchi T, Taketoh H et al. (1999) Elevated remnant-like lipoprotein particles in impaired glucose tolerance and type 2 diabetic patients. Diabetes Care 22: $152-156$

12. Laakso M, Barrett-Connor E (1989) Asymptomatic hyperglycaemia is associated with lipid and lipoprotein changes favoring atherosclerosis. Arteriosclerosis 9: 665-672

13. Salomaa VV, Tuomilehto J, Jauhiainen M et al. (1992) Hypertriglyceridemia in different degrees of glucose intolerance in a Finnish population-based study. Diabetes Care 15: 657-665

14. Laakso M, Sarlund H, Mykkanen L (1990) Insulin resistance is associated with lipid and lipoprotein abnormalities in subjects with varying degrees of glucose tolerance. Arteriosclerosis 10: 223-231

15. Haffner SM, Stern MP, Hazuda HP, Mitchell BD, Patterson JK (1990) Cardiovascular risk factors in confirmed prediabetic individuals. Does the clock for coronary heart disease start ticking before the onset of clinical diabetes? JAMA 263: 2893-2898

16. Walton C, Lees B, Crook D, Worthington M, Godsland IF, Stevenson JC (1995) Body fat distribution, rather than overall adiposity, influences serum lipids and lipoproteins in healthy men independently of age. Am J Med 99: 459-464

17. Mykkanen L, Laakso M, Pyorala K (1992) Association of obesity and distribution of obesity with glucose tolerance and cardiovascular risk factors in the elderly. Int J Obes Relat Metab Disord 16: 695-704

18. Després JP, Moorjani S, Lupien PJ, Tremblay A, Nadeau A, Bouchard C (1990) Regional distribution of body fat, plasma lipoproteins, and cardiovascular disease. Arteriosclerosis 10: 497-511

19. Yamashita S, Nakamura T, Shimomura I et al. (1996) Insulin resistance and body fat distribution. Diabetes Care 19: 287-291

20. Barrett-Connor E (1997) Does hyperglycaemia really cause coronary heart disease? Diabetes Care 20: 1620-1623

21. Report of the Expert Committee on the Diagnosis and Classification of Diabetes Mellitus (1997) Diabetes Care 20: 1183-1197

22. Behnke AR, Wilmore JH. (1974) Evaluation and regulation of body build and composition. In: Cliffs E (ed) Prentice-Hall, New Jersey, pp 20-37

23. Meneely GR, Kaltreider NL (1949) Volume of the lung determined by helium dilution. J Clin Invest 28: 129-139

24. Siri WE (1956) The gross composition of the body. Adv Biol Med Phys 4: 239-280

25. The Airlie (VA) consensus conference (1988) Standardization of anthropometric measurements. In: Lohman T, Roche A, Martorel R (eds) Human Kinetics Publishers, Champaign, IL: pp 39-80

26. Ferland M, Després JP, Tremblay A et al. (1989) Assessment of adipose tissue distribution by computed axial tomography in obese women: association with body density and anthropometric measurements. Br J Nutr 61: 139-148

27. Havel RJ, Eder H, Bragdon HF (1955) The distribution and chemical composition of ultracentrifugally separated lipoproteins in human serum. J Clin Invest 34: 1345-1353

28. Burstein M, Samaille J (1960) Sur un dosage rapide du cholestérol lié aux beta-lipoprotéines du sérum. Clin Chim Acta 5: 609-610

29. Laurell CB (1966) Quantitative estimation of proteins by electrophoresis in agarose gel containing antibodies. Anal Biochem 15: 45-52

30. Moorjani S, Dupont A, Labrie F et al. (1987) Increase in plasma high density lipoprotein concentration following complete androgen blockage in men with prostatic carcinoma. Metabolism 36: 244-250

31. Richterich R, Dauwalder H (1971) Zur bestimmung der plasmaglukosekonzentration mit der hexokinase-glucose6-phosphat-dehydrogenase-methode. Schweiz Med Wochenschr 101: 615-618

32. Desbuquois B, Aurbach GD (1971) Use of polyethylene glycol to separate free and antibody- bound peptide hormones in radioimmunoassays. J Clin Endocrinol Metab 37: 732-738

33. Matthews DR, Hosker JP, Rudenski AS, Naylor BA, Treacher DF, Turner RC (1985) Homeostasis model assessment: insulin resistance and beta-cell function from fasting plasma glucose and insulin concentrations in man. Diabetologia 28: 412-419

34. Phillips DI, Clark PM, Osmond C (1994) Understanding oral glucose tolerance: comparison of glucose or insulin measurements during the oral glucose tolerance test with specific measurements of insulin resistance and insulin secretion. Diabetic Med 11: 286-292

35. Després JP (1993) Abdominal obesity as important component of insulin-resistance syndrome. Nutrition 9: 452459

36. Hunter GR, Snyder SW, Kekes-Szabo T, Nicholson C, Berland L (1994) Intra-abdominal adipose tissue values associated with risk of possessing elevated blood lipids and blood pressure. Obes Res 2: 563-568

37. Walker M, Berrish TS, Stewart MW, Humphriss DB, Barriocanal L, Alberti KG (1997) Metabolic heterogeneity in impaired glucose tolerance. Metabolism 46: 914-917

38. Report of the expert committee on the diagnosis and classification of diabetes mellitus (1999) Diabetes Care 22 [Suppl 1]: S5-S19

39. Perry RC, Baron AD (1999) Impaired glucose tolerance. Why is it not a disease? Diabetes Care 22: 883-885

40. Laakso M, Lehto S (1998) Epidemiology of risk factors for cardiovascular disease in diabetes and impaired glucose tolerance. Atherosclerosis 137 [Suppl]: S65-S73

41. Haffner SM (1997) Impaired glucose tolerance, insulin resistance and cardiovascular disease. Diabet Med 14 [Suppl 3]: S12-S18

42. Geiss LS, Herman WH, Smith PJ (1995) Mortality in noninsulin-dependent diabetes. In: Harris MI CC, Stern MP, Boyko EJ, Reiber GE, Bennet PH (ed) Diabetes in America. Govt Printing Office, Washington, (NIH Publ. no. 95-1468): 233-257

43. Stamler J, Vaccaro O, Neaton JD, Wentworth D (1993) Diabetes, other risk factors, and 12-yr cardiovascular mortality for men screened in the Multiple Risk Factor Intervention Trial. Diabetes Care 16: 434-444

44. Wei M, Mitchell BD, Haffner SM, Stern MP (1996) Effects of cigarette smoking, diabetes, high cholesterol, and hypertension on all-cause mortality and cardiovascular disease mortality in Mexican Americans. The San Antonio Heart Study. Am J Epidemiol 144: 1058-1065

45. Donahue RP, Orchard TJ (1992) Diabetes mellitus and macrovascular complications. An epidemiological perspective. Diabetes Care 15: 1141-1155

46. MacGregor AS, Price JF, Hau CM, Lee AJ, Carson MN, Fowkes FG (1999) Role of systolic blood pressure and plasma triglycerides in diabetic peripheral arterial disease. The Edinburgh Artery Study. Diabetes Care 22: 453-458

47. Després JP (1998) The insulin resistance-dyslipidemic syndrome of visceral obesity: effect on patients' risk. Obes Res 6 [Suppl 1]: 8S-17S

48. Després JP (1991) Visceral obesity, insulin resistance, and related dyslipoproteinemias. In: Rifkin H, Colwell JA, Tay- 
lor SI (eds) Diabetes 1991: Elsevier Science Publishers, Amsterdam, pp 95-99

49. Lamarche B (1998) Abdominal obesity and its metabolic complications: implications for the risk of ischaemic heart disease. Coron Artery Dis 9: 473-481

50. Zamboni M, Armellini F, Cominacini L et al. (1994) Obesity and regional body-fat distribution in men: separate and joint relationships to glucose tolerance and plasma lipoproteins. Am J Clin Nutr 60: 682-687

51. Kissebah AH (1991) Insulin resistance in visceral obesity. Int J Obes 15 [Suppl 2]: 109-115

52. Cefalu WT, Wang ZQ, Werbel S et al. (1995) Contribution of visceral fat mass to the insulin resistance of aging. Metabolism 44: 954-959

53. Lamarche B, Tchernof A, Mauriège P et al. (1998) Fasting insulin and apolipoprotein B levels and low-density lipoprotein particle size as risk factors for ischemic heart disease. JAMA 279: 1955-1961
54. Helmrich SP, Ragland DR, Leung RW, Paffenbarger RS Jr (1991) Physical activity and reduced occurrence of non-insulin-dependent diabetes mellitus. N Engl J Med 325: $147-152$

55. Helmrich SP, Ragland DR, Paffenbarger RS Jr (1994) Prevention of non-insulin-dependent diabetes mellitus with physical activity. Med Sci Sports Exerc 26: 824-830

56. Smith SR, Zachwieja JJ (1999) Visceral adipose tissue: a critical review of intervention strategies. Int J Obes Relat Metab Disord 23: 329-335

57. Markovic TP, Campbell LV, Balasubramanian S et al. (1998) Beneficial effect on average lipid levels from energy restriction and fat loss in obese individuals with or without Type II diabetes. Diabetes Care 21: 695-700

58. Rankinen T, Kim SY, Perusse L, Després JP, Bouchard C (1999) The prediction of abdominal visceral fat level from body composition and anthropometry: ROC analysis. Int J Obes Relat Metab Disord 23: 801-809 